\title{
Thermal Properties of Aloe Vera Powder AND RHEOLOGY of ReCONSTITUTED Gels
}

\author{
C. I. Nindo, J. R. Powers, J. Tang
}

\begin{abstract}
Aloe vera (Aloe barbadensis $L$.) is a plant from the lily family that possesses therapeutic and antioxidant properties. Extracts from aloe vera leaves are widely used in skin care products, and recently in health drinks and supplements. Substandard aloe products arising from poor processing methods or adulteration with other compounds is a major problem for the aloe industry. Functional properties of aloe vera may be affected by processing procedures that involve heat or shearing action. In this study, aloe vera extract was dried using spray drying (SD), freeze drying (FD), and Refractance Window (RW) drying methods to investigate the effect of those methods on glass transition temperature $\left(T_{g}\right)$, total carbohydrates, reducing groups, particle size distribution, and viscosity of solutions formed after reconstitution with deionized water. The $T_{g}$ of $S D$ aloe was in the range of $65^{\circ} \mathrm{C} \pm 3.2^{\circ} \mathrm{C}$ compared to $70^{\circ} \mathrm{C}$ to $78^{\circ} \mathrm{C}$ for the latter two drying methods. Addition of corn maltodextrin contributed to shifts in $T_{g}$ of aloe powder. Solutions prepared from spray-dried aloe had the lowest viscosity, while freeze-dried and RW-dried counterparts had higher and nearly equal consistency. The activation energy for network formation of solutions reconstituted from $S D$ powder was $23.9 \pm 0.1 \mathrm{~kJ} \mathrm{~mol}^{-1}$, which was slightly lower than the $24.6 \pm 0.3$ and $24.7 \pm 0.4 \mathrm{~kJ} \mathrm{~mol}^{-1}$ obtained with FD and $R W$ drying, respectively.
\end{abstract}

Keywords. Aloe vera, Drying, Glass transition, Powder, Quality, Viscosity.

$\mathrm{E}$ xtracts from leaves of aloe vera (Aloe barbadensis L.) plant have been used for many years for topical treatment of skin injuries (including wounds and irritations) and as key ingredients in cosmetic formulations. The parenchyma tissue of aloe vera leaves contains over $98 \%$ water, with more than $60 \%$ of dry matter made up of high molecular weight polysaccharides (Femenia et al., 1999). In commercial processing of shelf-stable ingredients, this large amount of water must be removed with very little disruption to the high molecular weight polysaccharides (HMWP) that contribute to the plant's immune modulating properties. Qiu et al. (2000) showed that aloe polysaccharides with molecular weight (MW) between 50 to $200 \mathrm{kDa}$ possess significant immunoregulatory activity, while Leung et al. (2004) reported that high molecular weight and mannose content are essential for the antitumor potency of aloe vera. Although there is no consensus in the aloe industry regarding aloe MW fractions with the greatest immune modulating properties, it is important to evaluate the influence of processing methods on the molecular weight distribution of aloe polysaccharides. Freeze drying and Refractance Window (RW) drying both showed high retention of aloe polysac-

Submitted for review in September 2009 as manuscript number FPE 8227; approved for publication by the Food \& Process Engineering Institute Division of ASABE in June 2010. Presented at the 2007 ASABE Annual Meeting as Paper No. 076099.

The authors are Caleb I. Nindo, ASABE Member Engineer, Assistant Professor, School of Food Science, University of Idaho, Moscow, Idaho; Joseph R. Powers, Professor, School of Food Science, Washington State University, Pullman, Washington; and Juming Tang, ASABE Member Engineer, Professor, Department of Biological Systems Engineering, Washington State University, Pullman, Washington. Corresponding author: Caleb I. Nindo, School of Food Science, University of Idaho, Moscow, ID 83844; phone: 208-885-9683; fax: 208-885-2567; e-mail: cnindo@uidaho.edu. charides with MW in the range of 200 to $10 \mathrm{kDa}$ (Nindo and Tang, 2007).

Aloe vera has been used in the treatment of gastrointestinal problems (constipation and ulcers), arthritis, and headaches (Lee et al., 2000; Eshun and He, 2004; Bozzi et al., 2007). When used as a supplement, absorption of vitamins $C$ and $\mathrm{E}$ increased, and their concentration in blood plasma was prolonged when consumed with aloe vera (Vinson et al., 2005). Miranda et al. (2009) investigated the effect of drying temperature on vitamins $\mathrm{C}$ and $\mathrm{E}$ in aloe and suggested that their loss can be minimized by drying aloe between $60^{\circ} \mathrm{C}$ and $70^{\circ} \mathrm{C}$. The use of aloe vera as a nutritional supplement is gaining popularity because of studies that show its potential to support human health. However, proliferation of various products in the market that do not provide the needed benefits, mostly because of poor processing, handling, and/or adulteration with other substances, is a major concern to the aloe industry.

The current method of processing aloe products involves crushing, grinding, and pressing the entire leaf, or filleting to remove the outer leaf and grinding the gel to produce an aloe juice, followed by various steps of filtration and stabilization. The resulting solution is incorporated with other solutions or agents to produce pharmaceutical, cosmetic, or food products (Eshun and He, 2004; Waller et al., 2004). Spray drying is the most common method of producing aloe powder apart from few instances where freeze drying is used (Madan et al., 2009). Although any or all of those processing steps can affect the quality and shelf life of aloe vera products (Ramachandra and Rao, 2008), it is not possible to evaluate the drying methods without first establishing a common platform. Dried or concentrated products are definitely less bulky, easier to handle, and less susceptible to spoilage in long-term storage than those with high moisture, but it is important to ensure that quality is not impaired when applying 
any of the processing methods. Simal et al. (2000) evaluated both air-dried and lyophilized filets from aloe vera leaves for water retention capacity, swelling, and fat absorption capacity. They noted that the air temperatures investigated (from $40^{\circ} \mathrm{C}$ to $80^{\circ} \mathrm{C}$ ) had a greater effect on those properties than drying time. Other studies on drying of aloe vera have included determining the effect of temperature and relative humidity on drying time (Simal et al., 2000; Femenia et al., 2003; Ramachandra and Rao, 2009) and changes in physicochemical properties and antioxidant activity (Miranda et al., 2009). However, no studies were found that show the influence of drying methods on glass transition of aloe powder and rheological behavior of aloe vera solutions reconstituted from powder. Glass transition temperature is important for understanding the effect of plasticizers (water) on molecular mobility and stability of biopolymers, while rheological properties are important for elucidating changes in structure and consistency of solutions.

High shear forces experienced under spray-drying conditions can alter the desirable structural characteristics of polysaccharides found in aloe. Because maltodextrin has high glass transition temperature and is tasteless, odorless, and non-hygroscopic (Adhikari et al., 2004), it is frequently used as a drying aid in spray drying to avoid stickiness and to avoid caking of the resulting powder. Some unscrupulous vendors of aloe products adulterate aloe powder with maltodextrin because both are polysaccharides with high molecular weights and have indistinguishable properties in powder form (Bozzi et al., 2007; Ho et al., 1998). Due to increased demand for aloe vera gel for use in functional foods such as health drinks and certain alcoholic beverages, $\mathrm{He}$ et al. (2005) suggested some specific procedures for processing of aloe vera juice to meet the ISO 2000 food quality standards.

Different analytical methods have been used to detect the presence of maltodextrin and other adulterants in commercial aloe vera products. High-performance liquid chromatography with size exclusion is the most popular technique used, but in certain cases the chromatogram peaks may not separate well enough to clearly indicate the presence of maltodextrin (Turner et al., 2004). Bozzi et al. (2007) used nuclear magnetic resonance (NMR) spectrometry to analyze the quality and authenticity of commercial aloe vera gels and powders and were able to determine the freshness of aloe gels from organic acid profiles. With the latest developments in differential scanning calorimetry (DSC) utilizing modulated heating and providing very flat baselines, the existence of weak transitions in food and pharmaceutical products have become easier to detect. Modulated DSC is very fast, and very small sample sizes $(<10 \mathrm{mg})$ can be used to analyze the quality and authenticity of commercial aloe vera gels and powders. Glass transition $\left(T_{g}\right)$ is a second-order phenomenon that occurs within a specific temperature range when polymeric materials undergo a heating or cooling process. For most biological materials, the $T_{g}$ is influenced by the presence of water (water activity) and other plasticizers. Its measurement is important for predicting storage stability (critical temperatures), rehydration, and other functional properties that may be affected by those plasticizers.

Viscosity measurement at low strain rates is important to ensure that testing is within the linear viscoelastic range for better elucidation of structural changes in the material. In this way, the formation or breakdown of gel networks can be measured at low frequencies, and the data obtained can be used to characterize the material. Very little information is available on the rheological behavior of aloe vera gels. Yaron et al. (1992) used a Haake RV2 viscometer equipped with coaxial cylinders to investigate the stabilization effect of red microalgae and xanthan gum on aloe vera gel. Their objective was to obtain a homogeneous aloe vera exudate with extended shelf life. Maintaining freshly extracted aloe juice in a stable condition is difficult, especially in cases where aloe plantations are located far from processing facilities. The rheological properties of aloe vera juice may change dramatically if there is prolonged time between juice extraction and when it is concentrated (stabilized) before converting it into powder. Oxidation and continuation of native enzyme activity within that period may cause product separation and deterioration.

The objective of this research was to study the effect of different drying methods and addition of maltodextrin on the glass transition of aloe powders and on the rheological behavior of aloe vera solutions reconstituted from powder. The measurement of thermal properties (changes in heat flow or heat capacity) and rheological properties under controlled stress-strain conditions may provide insights into the effect of processing, and the addition of processing aids, on the quality of aloe vera normally used in cosmetics, nutritional supplements, and foods. Aloe vera dried using the three drying methods and a commercial gel was evaluated.

\section{Materials ANd Methods}

Freshly extracted and concentrated aloe vera juice containing $87 \%$ water (wet basis) was obtained from a commercial processor. The material was shipped under refrigerated conditions in $19 \mathrm{~L}$ (5 gal) buckets for drying using pilot freeze and spray dryers at Washington State University (Pullman, Wash.) and a Refractance Window dryer at MCD Technologies, Inc. (Tacoma, Wash.). Some of the fresh material was retained for rheological experiments. The freeze dryer (Freeze Mobile 24, Vertis Co., Inc., Gardiner, N.Y.) was operated at plate heating temperature $21^{\circ} \mathrm{C}$ and absolute pressure of $3.3 \mathrm{kPa}$. For better yield of powder, the spray dryer (Anhydro, Attleboro Falls, Mass.) inlet and outlet conditions were adjusted between $170^{\circ} \mathrm{C}$ to $190^{\circ} \mathrm{C}$ and $80^{\circ} \mathrm{C}$ to $90^{\circ} \mathrm{C}$, respectively. Refractance Window drying involved spreading the aloe extract on a transparent plastic conveyor belt that is heated by hot water (Nindo et al., 2003). The temperature of the circulating hot water, which provided thermal energy for drying, was in the range of $95^{\circ} \mathrm{C}$ to $98^{\circ} \mathrm{C}$, while the average temperature of the aloe was between $60^{\circ} \mathrm{C}$ and $70^{\circ} \mathrm{C}$ with the belt moving at a constant speed of $0.1 \mathrm{~m} \mathrm{~s}^{-1}$.

Glass transition temperature for pure dried aloe and for aloe powder uniformly mixed with $10 \mathrm{DE}$ corn maltodextrin in the ratio of 99:1 and 95:5 (g/g dry solids) was then determined using a Q200 modulated DSC (TA Instruments, New Castle, Del.). These samples are referred to as pure aloe, $1 \%$ maltodextrin, and 5\% maltodextrin, respectively. The samples (approx. $10 \mathrm{mg}$ ) were placed in aluminum Tzero pans,

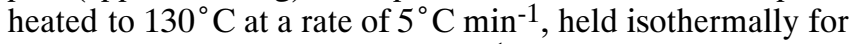
$2 \mathrm{~min}$, cooled to $-10^{\circ} \mathrm{C}$ at $5^{\circ} \mathrm{C} \mathrm{min}-1$, held again isothermally for $15 \mathrm{~min}$, and then finally ramped to $130^{\circ} \mathrm{C}$ at $5^{\circ} \mathrm{C} \mathrm{min}-1$ before cooling down to ambient conditions. The heating and cooling rates are similar to those used by Descamps et al. (2009). At least three replicates were obtained for each sam- 
ple. The resulting DSC thermograms were analyzed using Universal Analysis 2000 (version 4.5, TA Instruments, New Castle, Del.). Reversed heat flow curves were used to detect the glass transition temperature for the materials.

The flow behavior of fresh aloe extract was measured in a controlled stress-strain rheometer (AR2000, TA Instruments, New Castle, Del.) with continuous temperature ramp $\left(10^{\circ} \mathrm{C}, 20^{\circ} \mathrm{C}, 30^{\circ} \mathrm{C}, 40^{\circ} \mathrm{C}\right.$, and $\left.50^{\circ} \mathrm{C}\right)$. About $19 \mathrm{~mL}$ of extract was put in concentric cylinder geometry and conditioned at $10^{\circ} \mathrm{C}$ for $2 \mathrm{~min}$ before ramping to the required temperature and applying shear rates from 0 to $300 \mathrm{~s}^{-1}$. The powders obtained by the three drying methods were reconsti- tuted with deionized (DI) water to $87 \%$ w.b. water content (same as fresh aloe extract) and tested similarly. For those incorporating maltodextrin, the solutions were prepared by adding maltodextrin at $1 \%$ and $5 \%$ of aloe solids on dry basis. The data generated was analyzed using Rheology Advantage software (version 5.7) provided by the manufacturer. The aloe particle size was determined using an optical particle sizer (Accusizer 780, Particle Size Systems, Santa Barbara, Cal.). The powder was dissolved in DI water by stirring with a magnetic stirrer for $2 \mathrm{~min}$, and then $0.4 \mathrm{~mL}$ was pulled with a syringe and injected in $400 \mathrm{~mL}$ of DI water to determine the particle size distribution.
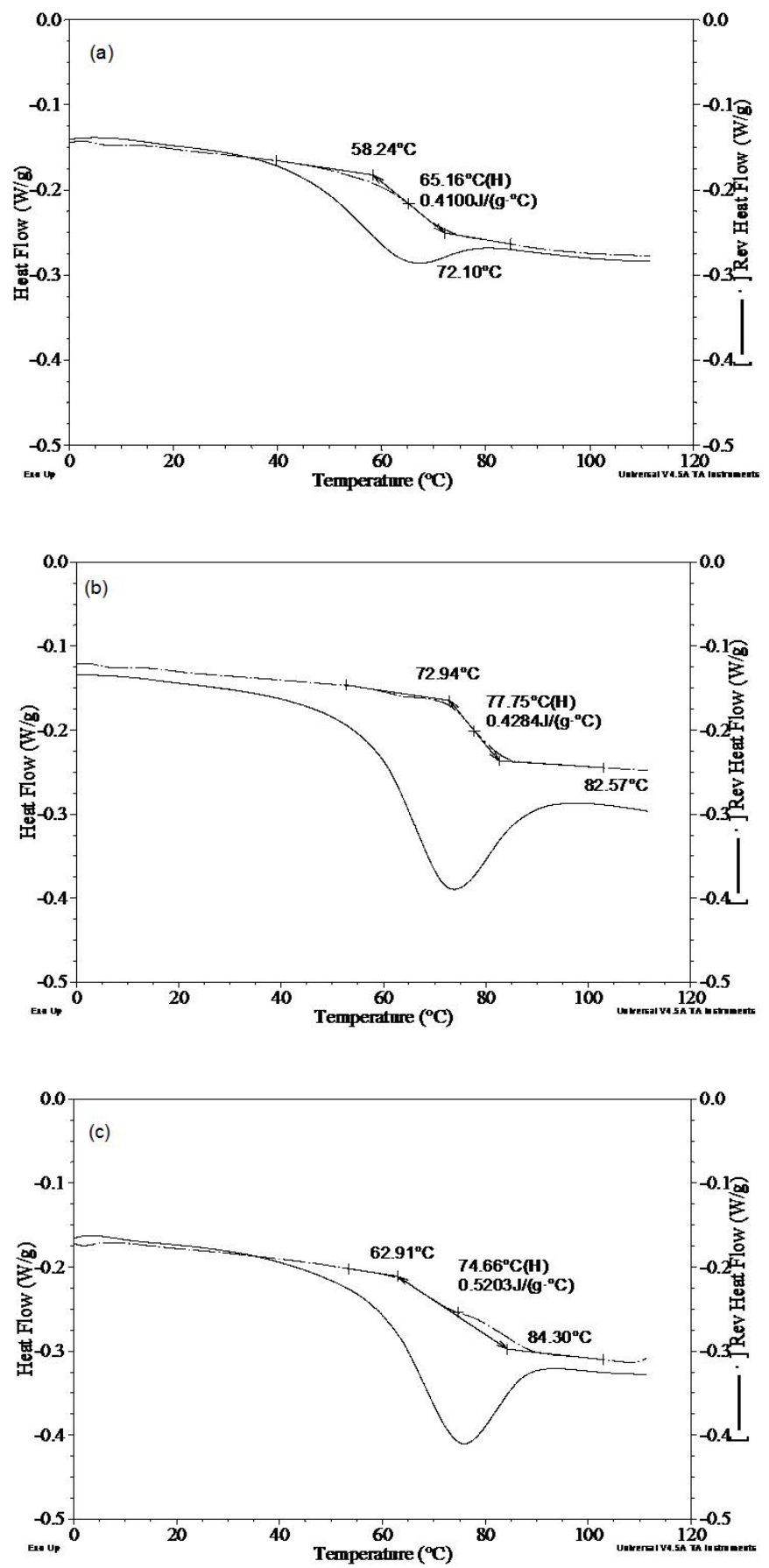

Figure 1. Typical total and reversed heat flow curves for (a) spray-dried, (b) freeze-dried, and (c) RW-dried aloe powders indicating onset, midpoint, and endpoint of glass transition. 
To determine total carbohydrates in aloe extract before drying and for powders, phenol sulfuric acid assay (5\% aqueous phenol and $95.5 \%$ sulfuric acid) was used (Dubois et al., 1956). First, samples containing $100 \mathrm{mg}$ of aloe solids were weighed and transferred into a $50 \mathrm{~mL}$ Erlenmeyer flask, after which $25 \mathrm{~mL}$ DI water was added, followed by mixing on a shaker $(60 \mathrm{rpm})$ for $30 \mathrm{~min}$. Secondly, $2 \mathrm{~mL}$ of glucose standard solutions was prepared and put in small glass tubes. Then, $1 \mathrm{~mL}$ of $5 \%$ aqueous phenol plus $5 \mathrm{~mL}$ of $95.5 \%$ sulfuric acid was added. This was vortexed at $1600 \mathrm{rpm}$ for $10 \mathrm{~s}$ and then allowed to stand for $10 \mathrm{~min}$ at room temperature. The tubes were transferred into a water bath set at $28^{\circ} \mathrm{C}$ and conditioned for another $20 \mathrm{~min}$ before absorbance was measured at $490 \mathrm{~nm}$. The solubilized aloe was analyzed in a similar way as for the standard. For reducing group assay, equal volumes of glucose standard and 3,5 dinitrosalicyclic acid were mixed and heated in boiling water for $5 \mathrm{~min}$. The tubes were cooled in running tap water, further diluted with $5 \mathrm{~mL}$ of DI water, and vortexed briefly. Absorbances of the standard and samples were read at $540 \mathrm{~nm}$. The results are reported as percent carbohydrates $(\mathrm{CHO})$ and reducing group, and their ratio reflects the change in molecular weight.

\section{RESUlTS AND DiscuSSION}

Figure 1 shows typical modulated DSC thermograms depicting the onset of glass transition and enthalpy peaks observed for spray-dried (SD), freeze-dried (FD), and RW-dried aloe powder. These curves were obtained after the powders were equilibrated under low humidity. The average water activity $\left(a_{w}\right)$ for the SD, FD, and RW-dried powders were 0.114 , 0.086 , and 0.167 , respectively. The $a_{w}$ was measured at $23.8^{\circ} \mathrm{C}$ using an Aqualab 3TE water activity meter (Decagon Devices, Pullman Wash.). The enthalpy changes during glass transition events for FD and RW-dried aloe were nearly the same but higher than SD samples. It is likely that spray drying caused more break-down of the polysaccharide networks; therefore, a relatively smaller enthalpy change was required compared to the other two drying methods.

For pure aloe, the $T_{g}$ values of spray-dried samples were generally lower, with an onset point around $58.2^{\circ} \mathrm{C}$ and midpoint of $65.2^{\circ} \mathrm{C}$ (average $65.9^{\circ} \mathrm{C} \pm 3.2^{\circ} \mathrm{C}$,) compared to that of either freeze-dried or RW-dried samples, with midpoint $T_{g}$ in the range of $70^{\circ} \mathrm{C}$ to $78^{\circ} \mathrm{C}$ (fig. 1). During the spray-drying process, it is possible that aloe polysaccharides were subjected to high shear forces, which can contribute to breakdown of structure, and hence reduce the health benefits derived from their use (Femenia et al., 2003). The water activity values were very low for all the aloe dried by the three different methods and, therefore, most likely did not affect the $T_{g}$.

A comparison of DSC thermograms for freeze-dried aloe powders indicates a clear glass transition for pure aloe $(0 \%$ maltodextrin), while that containing $5 \%$ maltodextrin has similar $T_{g}$ but with a maltodextrin peak superimposed on it (fig. 2). The $T_{g}$ for the $10 \mathrm{DE}$ maltodextrin is much higher than that of pure aloe or that of 95:5 aloe solids to maltodextrin mixture. The commercial aloe vera herbal supplement (PharmAssure, Inc, Phoenix, Ariz.) containing aloe vera inner gel and other ingredients (soybean oil, gelatin, and glycerin) showed an enthalpy peak around $50^{\circ} \mathrm{C}$ and was distinctly different from the other solutions investigated, probably because of those other ingredients.

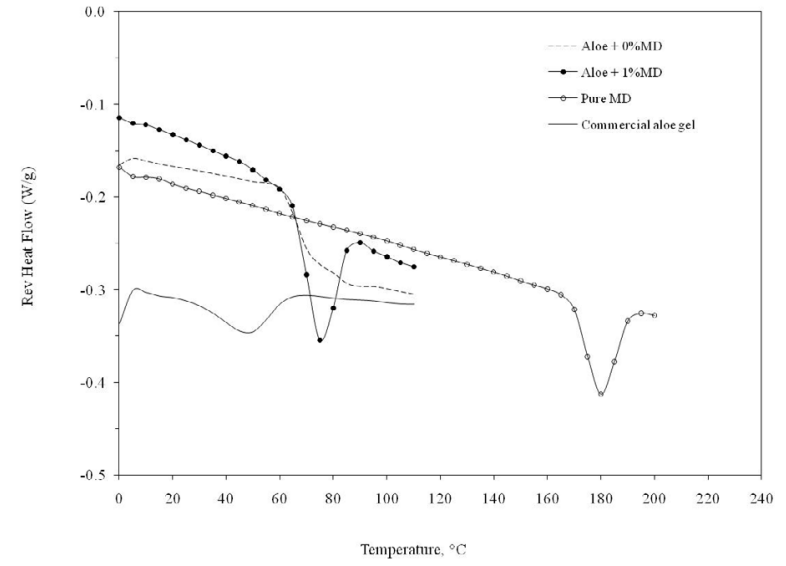

Figure 2. DSC heat flow thermograms for commercial aloe vera gel, freeze-dried aloe powder with and without maltodextrin, and pure maltodextrin.

Table 1 shows the enthalpy changes of the variously dried aloe powders containing maltodextrin. Aloe powder composed of 5\% maltodextrin showed slightly lower heat capacity change over the transition.

Drying methods significantly influenced $T_{g}$. However, for each drying method, the addition of maltodextrin at either $1 \%$ or $5 \%$ did not affect the $T_{g}$ value significantly (fig. 3). For spray-dried aloe, the $T_{g}$ was nearly the same for pure aloe and for samples with $1 \%$ and $5 \%$ maltodextrin. The results suggest that modulated DSC was sensitive in detecting the effect of drying methods on possible changes in aloe vera polymers.

BeMiller and Whistler (1996) reported that the percentage of total carbohydrates and reducing groups may be a good in-

Table 1. Glass transition temperature and enthalpy change for aloe vera with different amounts of maltodextrin (MD).

\begin{tabular}{cccccc}
\hline & \multicolumn{2}{c}{$\begin{array}{c}\text { Glass Transition } \\
\text { Drying }\end{array}$} & & \multicolumn{2}{c}{$\begin{array}{c}\text { Enthalpy Change } \\
\left(\mathrm{J} \mathrm{g} \mathrm{g}^{-1}{ }^{\circ} \mathrm{C}^{-1}\right)\end{array}$} \\
\cline { 2 - 3 } \cline { 5 - 6 } \cline { 5 - 6 } \cline { 5 - 6 } Method & $1 \% \mathrm{MD}$ & $5 \% \mathrm{MD}$ & & $1 \% \mathrm{MD}$ & $5 \% \mathrm{MD}$ \\
\hline Freeze drying & 27.53 & 28.58 & & 0.311 & 0.307 \\
& \pm 3.79 & \pm 0.76 & & \pm 0.082 & \pm 0.058 \\
\hline RW drying & 46.02 & 46.20 & & 0.366 & 0.358 \\
& \pm 0.62 & \pm 0.23 & & \pm 0.050 & \pm 0.013 \\
\hline Spray drying & 65.76 & 69.79 & & 0.252 & 0.179 \\
& \pm 0.95 & \pm 4.98 & & \pm 0.013 & \pm 0.032 \\
\hline
\end{tabular}

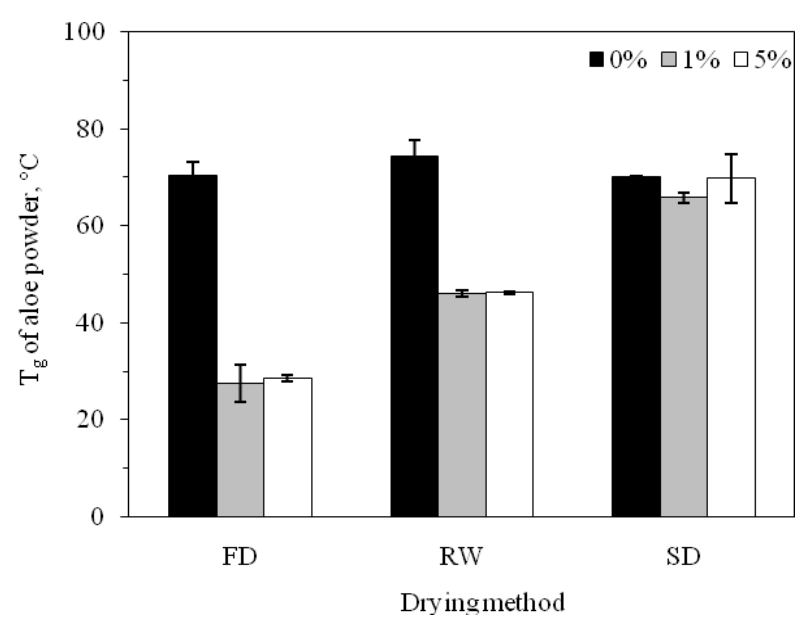

Figure 3. Effect of maltodextrin and drying method on $T_{g}$ of aloe powder. 


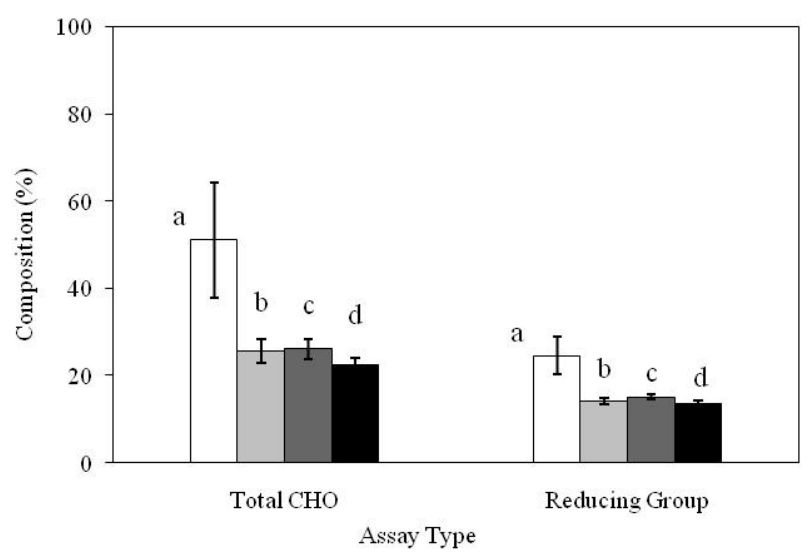

Figure 4. Distribution of total carbohydrates and reducing groups in (a) fresh aloe gel and in aloe powder after (b) freeze drying, (c) RW drying, and (d) spray drying.

dicator of the severity of different processing methods, as they can lead to depolymerization. In the current study, the total carbohydrates and reducing groups were not greatly affected by the three drying methods investigated (fig. 4). Although products undergo high shear during spray drying, the total carbohydrate content was not much affected. The results obtained for total $\mathrm{CHO}$ content and reducing groups may have been affected by the sample preparation process even though the solubilization protocol was standardized for all samples. Miranda et al. (2009) found low amounts of available carbohydrates in fresh and rehydrated aloe (1.07 and
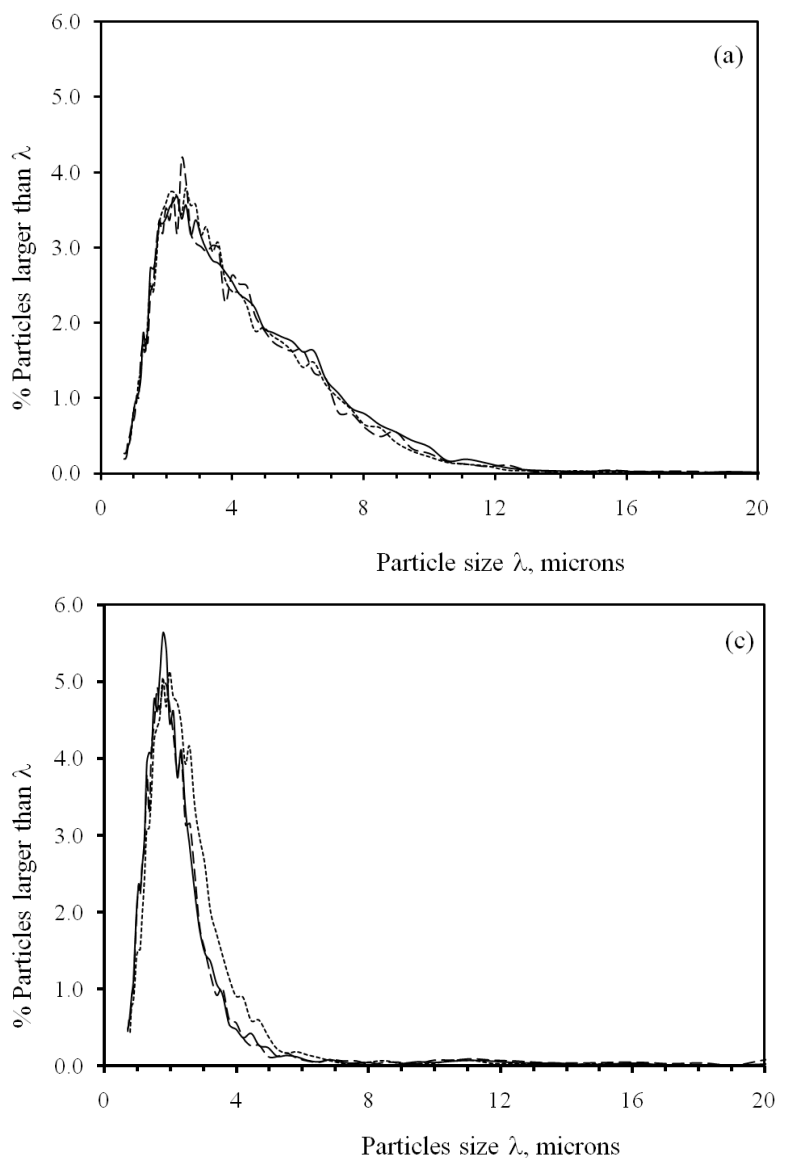

$4.26 \mathrm{~g}$ per $100 \mathrm{~g}$ dry matter, respectively), thus indicating that ingestion of aloe does not contribute significant calories to the body.

Spray drying resulted in finer powders, and the material probably underwent some structural breakdown, probably because of high shear forces and temperature conditions experienced during the process (fig. 5). Compared to aloe particles from the other drying methods, spray drying resulted in almost no particles larger than $4.5 \mu \mathrm{m}$ but showed the largest fraction (about 5\%) of particles larger than $2 \mu \mathrm{m}$. This may be due to the shearing action that led to a narrowing of particle size distribution. The particle size distributions for FD and RW-dried aloe were similar, while that of the native polymers was much broader, with more particles in the 4 to $16 \mu \mathrm{m}$ range being observed. A profile for the fraction of particles smaller than approximately $0.7 \mu \mathrm{m}$ was observed in all cases, and this probably came from the fine particles in purified water used as a blank during the analysis. It can be argued that the FD and RW drying methods do not cause product shear when compared to spray drying and that both allow for minimal to non-use of drying aids and hence are capable of producing dehydrated products with high quality.

At temperatures between $10^{\circ} \mathrm{C}$ and $50^{\circ} \mathrm{C}$, the viscosity of aloe solutions $\left(0.15 \mathrm{~g}\right.$ aloe solids $\mathrm{g}^{-1}$ water $)$ remained fairly constant as shear rate was increased from 0 to $300 \mathrm{~s}^{-1}$. This is indicative of Newtonian flow behavior for the shear rates typically needed for pumping fluids that may be susceptible to structural modifications at high shear rates. The flow behavior of freshly extracted aloe solutions was also compared
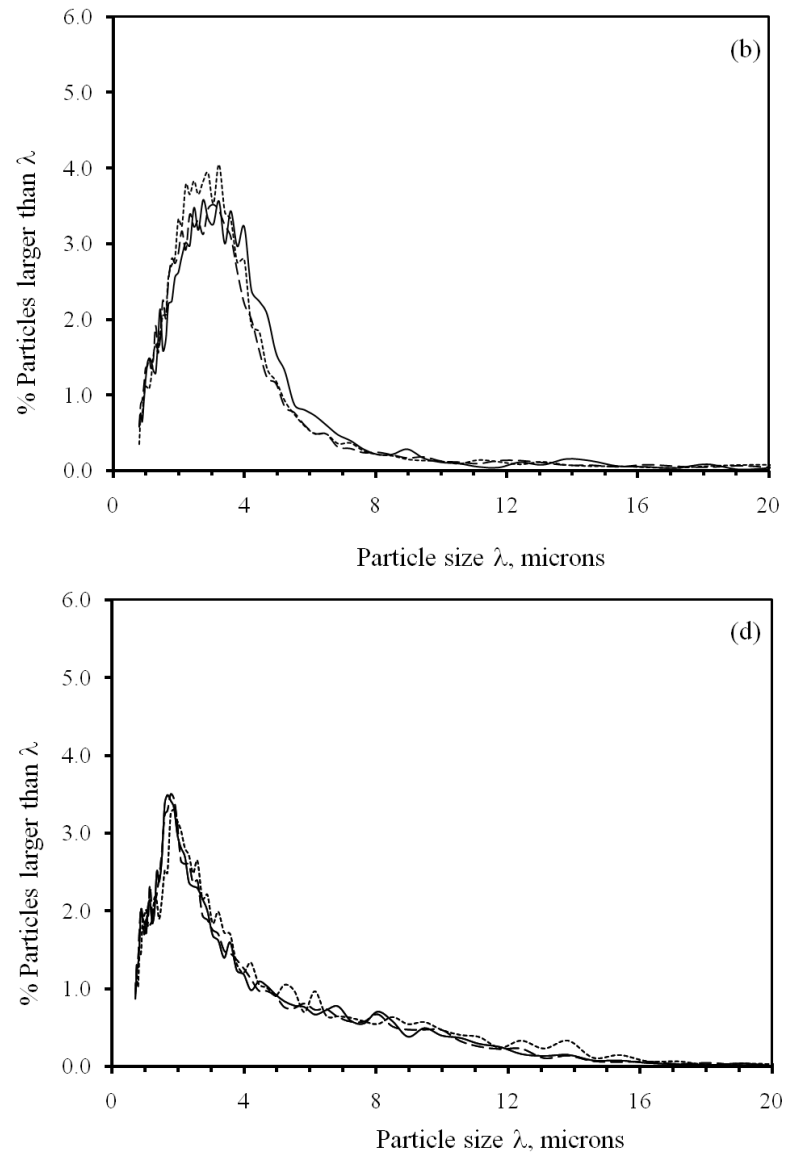

Figure 5. Particle size distribution of (a) RW-dried, (b) freeze-dried, (c) spray-dried, and (d) freshly extracted aloe gel. 

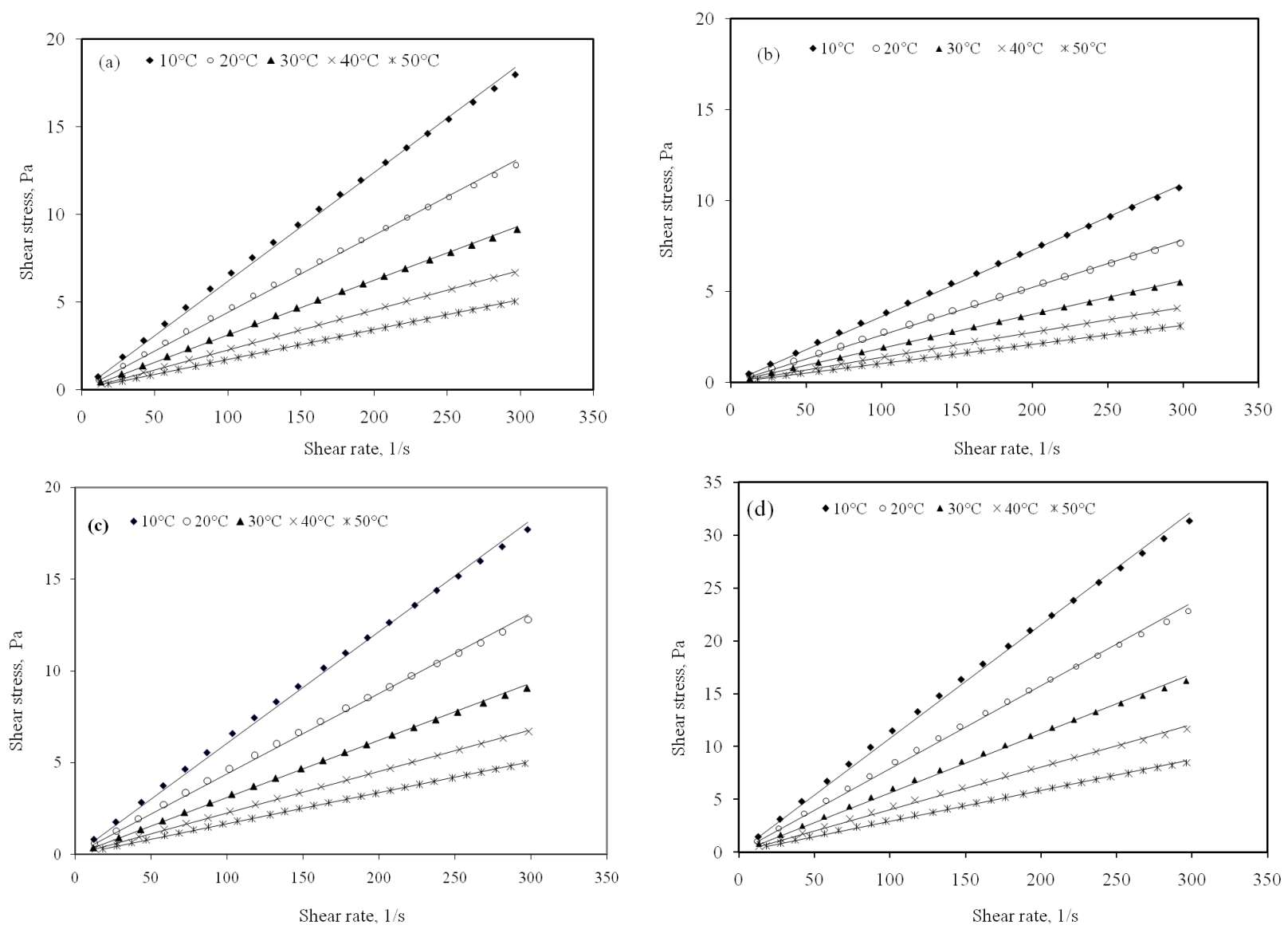

Figure 6. Rheological models for aloe solutions prepared from (a) freeze-dried, (b) spray-dried, and (c) RW-dried aloe compared to (d) native aloe solution containing $0.15 \mathrm{~g}$ aloe solids $\mathrm{g}^{-1}$ water. At least three analytical replicates were run at each temperature.

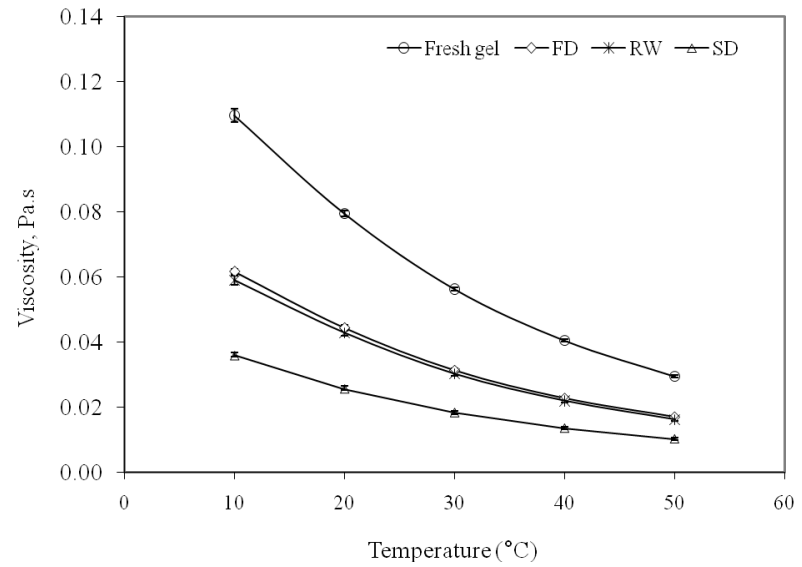

Figure 7. Effect of temperature on viscosity of fresh aloe vera extract and solutions reconstituted from freeze-dried (FD), Refractance Windowdried (RW), and spray-dried (SD) aloe powder. All measurements were at $100 \mathrm{~s}^{-1}$.

with that of suspensions made by solubilizing the dried powders (fig. 6). The viscosity of fresh aloe solutions at $10^{\circ} \mathrm{C}$ was nearly twice that of the solutions prepared from powders at the same temperature. This can be attributed to the mixing and stirring that occur during the extraction process followed by the drying treatments that caused breakdown of native polysaccharide networks, hence lowering the viscosity. Solutions prepared from freeze-dried and RW-dried powders exhibited Newtonian flow behavior, as shown in figure 6 . This
Table 2. Viscosity of aloe solutions prepared from powder compared to native gel $(\mathrm{mPa} \cdot \mathrm{s})$.

\begin{tabular}{lccccc}
\hline Source & $10^{\circ} \mathrm{C}$ & $20^{\circ} \mathrm{C}$ & $30^{\circ} \mathrm{C}$ & $40^{\circ} \mathrm{C}$ & $50^{\circ} \mathrm{C}$ \\
\hline Native gel & $109.6 \pm 2.0$ & $79.5 \pm 0.8$ & $56.3 \pm 0.5$ & $40.6 \pm 0.4$ & $29.6 \pm 0.3$ \\
Freeze-dried & $61.7 \pm 0.8$ & $44.4 \pm 0.9$ & $31.3 \pm 0.6$ & $22.8 \pm 0.5$ & $17.0 \pm 0.2$ \\
RW-dried & $59.0 \pm 1.5$ & $42.9 \pm 0.9$ & $30.3 \pm 0.7$ & $22.0 \pm 0.6$ & $16.3 \pm 0.5$ \\
Spray-dried & $36.2 \pm 0.2$ & $25.9 \pm 0.6$ & $18.5 \pm 0.5$ & $13.6 \pm 0.4$ & $10.3 \pm 0.2$ \\
\hline
\end{tabular}

is possibly because these two drying processes caused less disruption to the polysaccharide network structure when compared to the spray-drying method, which involves some shearing action (Tewa-Tagne et al., 2007). The viscosity of solutions from reconstituted spray-dried aloe powders was the lowest at all the temperatures investigated (fig. 7 and table 2). The data in table 2 are based on Newtonian flow behavior and were determined using the following model:

$$
\sigma=\eta(\dot{\gamma})
$$

where $\sigma$ is shear stress (measured in Pa during analysis but converted to $\mathrm{mPa}$ in table 1 for clarity), $\dot{\gamma}$ is shear rate $\left(\mathrm{s}^{-1}\right)$, and $\eta$ is viscosity ( $\mathrm{mPa} \cdot \mathrm{s})$. The viscosity values corresponding to the lowest and highest temperatures were from 36.2 to $10.3 \mathrm{mPa} \cdot \mathrm{s}$ for spray-dried material, compared to 59.0 to $16.3 \mathrm{mPa} \cdot \mathrm{s}, 61.7$ to $17.0 \mathrm{mPa} \cdot \mathrm{s}$, and 109.6 to $29.6 \mathrm{mPa} \cdot \mathrm{s}$ for $\mathrm{RW}$, freeze-drying, and fresh aloe extract, respectively.

The Arrhenius equation (eq. 2) was used to model the influence of temperature on the rheological behavior of aloe solutions before drying (referred to as fresh gel) and solutions 


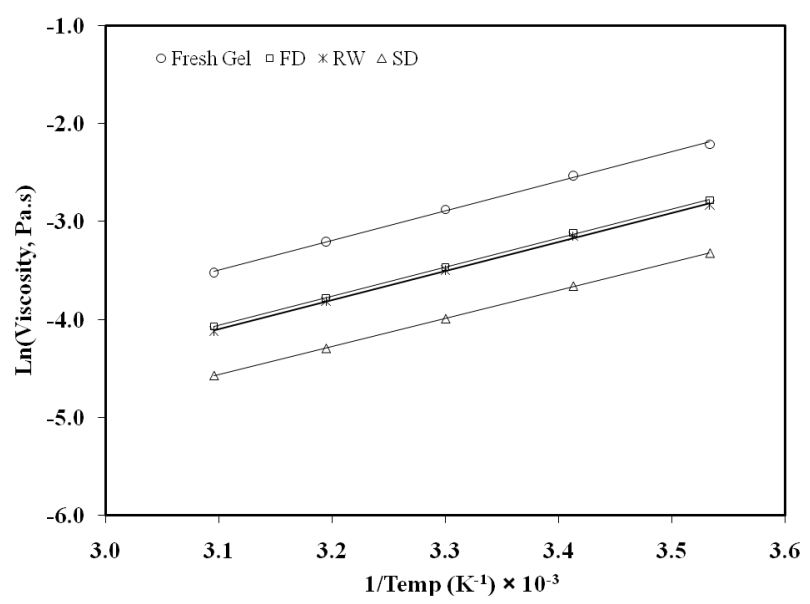

Figure 8. Change in viscosity of aloe vera fresh gel and that of solutions prepared from from freeze-dried (FD), Refractance Window-dried (RW), and spray-dried (SD) powders. All measurements were at shear rate of $100 \mathrm{~s}^{-1}$.

prepared from dried powders reconstituted to $87 \%$ moisture content (same as the freshly extracted gel):

$$
\eta=\eta_{0} * \operatorname{Exp}\left[\frac{E_{a}}{R}\left(\frac{1}{T}-\frac{1}{T_{0}}\right)\right]
$$

where $\eta$ is the measured viscosity $(\mathrm{Pa} \cdot \mathrm{s}), \eta_{0}$ is the viscosity at reference temperature $T_{0}\left(25^{\circ} \mathrm{C}\right), E_{a}$ is the activation energy $\left(\mathrm{kJ} \mathrm{mol}^{-1}\right)$, and $R$ is the universal gas constant $\left(\mathrm{kJ} \mathrm{mol}{ }^{-1}\right.$ $\mathrm{K}^{-1}$ ). The Arrhenius plots, obtained at $100 \mathrm{~s}^{-1}$, are shown in figure 8 . The activation energy for solutions formed from spray-dried powder was $23.9 \pm 0.1 \mathrm{~kJ} \mathrm{~mol}^{-1}(\mathrm{p}=0.05)$, compared to $24.6 \pm 0.3 \mathrm{~kJ} \mathrm{~mol}^{-1}$ for $\mathrm{FD}, 24.7 \pm 0.4 \mathrm{~kJ} \mathrm{~mol}^{-1}$ for $\mathrm{RW}$, and $25.0 \pm 0.5 \mathrm{~kJ} \mathrm{~mol}^{-1}$ for native fresh gel in which the networks were less affected by shearing and thermal treatment. At that same level of confidence, the consistency coefficients for fresh gel and reconstituted FD, RW, and SD powders were $0.066,0.037,0.035$, and $0.022 \mathrm{~Pa} \cdot \mathrm{s}$, respectively.

When the specific viscosity $\left(\eta_{n s}\right)$ was plotted against the product of solution viscosity (measured at $10^{\circ} \mathrm{C}, 20^{\circ} \mathrm{C}, 30$, $40^{\circ} \mathrm{C}$, and $50^{\circ} \mathrm{C}$ ) and concentration of maltodextrin in the reconstituted solutions ( $1 \%$ and $5 \%$ aloe polymer solids), the effect of maltodextrin addition was clearly delineated (fig. 9). Specific viscosity gives an indication of viscosity increment due to solute, while the parameter $c[\eta]$ can be taken as a measure of the extent of overlapping between polymer molecules (Dogan and Kokini, 2007). It is this overlapping or networking that influences the solution viscosity, and hence its structure. Maltodextrin concentration higher than $5 \%$ of total solids (considered excessive) was not investigated, while the solution temperature was limited to $50^{\circ} \mathrm{C}$ to avoid gelation (Loret et al., 2004). The specific viscosity $\left(\eta_{n s}\right)$ increased exponentially with $c[\eta]$ according to the relationship:

$$
\eta_{n s}=\alpha^{*} \ln \{c(\eta)\}+\beta
$$

where $\alpha$ and $\beta$ are physical constants that describe the hydrodynamic behavior of aloe and maltodextrin polysaccharides solutions. The respective values of $\alpha$ and $\beta$ were 27.3 and 273.7 for spray-dried aloe containing $1 \%$ MD compared to

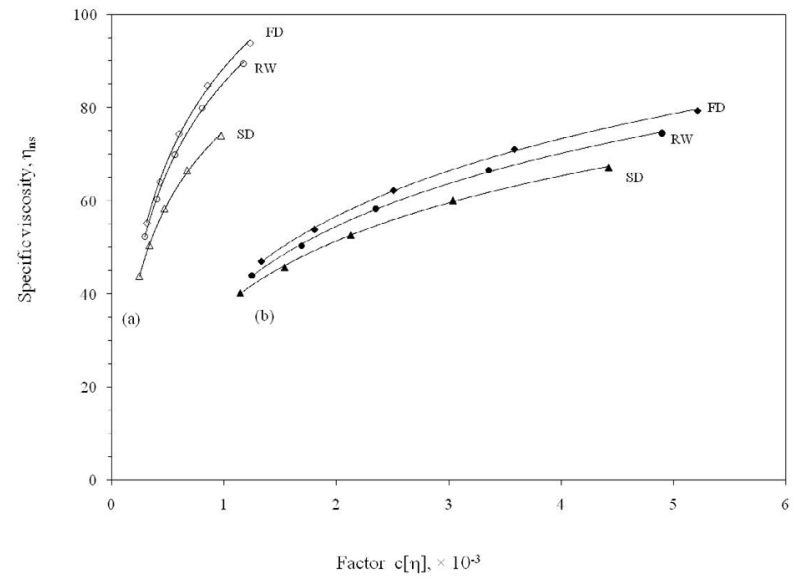

Figure 9. Effect of maltodextrin addition at (a) $1 \%$ and (b) $5 \%$ of aloe polymer solids fraction on specific viscosity of aloe solutions reconstituted from freeze-dried (FD), spray-dried (SD) and Refractance Window-dried (RW) powders.

22.6 and 195.1 for those with $5 \% \mathrm{MD}\left(\mathrm{r}^{2}=0.995\right.$ in both cases). The RW-dried and FD material also showed similar patterns (fig. 9). This model may be used to characterize aloe vera powder based on rheological properties exhibited after reconstitution. Aloe powder quality standards may be specified to include viscosity of gels with defined solids content. The determination of rheological model parameters $\alpha$ and $\beta$ can allow the quality of aloe gels reconstituted from powder to be verified for various uses, such as beverages, drug delivery, cosmetics, and other therapeutic purposes.

\section{Conclusions}

Glass transition temperature $\left(T_{g}\right)$ of aloe vera powder and the flow behavior of solutions reconstituted from powder were investigated with and without maltodextrin. The $T_{g}$ was not sensitive to small amounts $(1 \%$ to $5 \%)$ of maltodextrin added to aloe vera powder, but peaks similar to maltodextrin were observed. Such changes in the reversed heat flow, as opposed to total heat flow patterns, may be used as a quality check for aloe powder. The viscosity of reconstituted spraydried aloe powder was smaller than that obtained with the other two drying methods. The activation energy for network formation of spray-dried aloe powder, based on viscosity after reconstitution, was the lowest at $23.9 \pm 0.1 \mathrm{~kJ} \mathrm{~mol}^{-1}$, compared to $24.6 \pm 0.3,24.7 \pm 0.4$, and $25.0 \pm 0.5 \mathrm{~kJ} \mathrm{~mol}^{-1}$ for freeze-dried, RW-dried, and fresh aloe extract, respectively. The similarity in flow behavior of aloe solutions reconstituted from freeze-dried and RW-dried powder and the closeness to rheology of fresh extract suggest that the two drying methods are less disruptive to the physical structure of aloe. The particle size distributions of freeze-dried and RWdried aloe powders were more or less similar to the native gel when compared to spray-dried aloe powder, which had a narrower distribution.

\section{ACKNOWLEDGEMENTS}

The authors would like to thank Washington Technology Center for the funding support for this work. We are also grateful to MCD Technologies, Inc., for their assistance in carrying out the Refractance Window drying experiments at their facility in Tacoma, Washington. 


\section{REFERENCES}

Adhikari, B., T. Howes, B. R. Bhandari, and V. Truong. 2004. Effect of addition of maltodextrin on drying kinetics and stickiness of sugar and acid-rich foods during convective drying: Experiments and modeling. J. Food Eng. 62(1): 53-68.

BeMiller, J. N., and R. L. Whistler. 1996. Carbohydrates. In Food Chemistry, 181-184. O. R. Fennema, ed. New York, N.Y.: Marcel Dekker.

Bozzi, A., C. Perrin, S. Austin, and F. Arce Vera. 2007. Quality and authenticity of commercial aloe vera gel powders. Food Chem. 103(1): 22-33.

Descamps, N., S. Palzer, and Zuercher. 2009. The amorphous state of spray-dried maltodextrin: Sub-sub- $T_{g}$ enthalpy relaxation and impact of temperature and water annealing. Carbohydrate Res. 344(1): 85-90.

Dogan, H., and J. L. Kokini. 2007. Rheological properties of foods. In Handbook of Food Engineering, 1-124. D. R. Heldman and D. B. Lund, eds. Boca Raton, Fla.: CRC Press.

Dubois, M., K. A. Gilles, J. K. Hamilton, P. A. Rebers, and F. Smith. 1956. Colorimetric method for determination of sugars and related substances. Anal. Chem. 28(3): 350-356.

Eshun, K., and Q. He. 2004. Aloe vera: A valuable ingredient for the food, pharmaceutical, and cosmetic industries: A review. Crit. Rev. Food Sci. and Nutr. 44(2): 91-96.

Femenia, A., E. S. Sanchez, S. Simal, and C. Rosello. 1999. Compositional features of polysaccharides from aloe vera (Aloe barbadensis Miller) plant tissues. Carbohydrate Polymers 39(2): 109-117.

Femenia, A., P. Garcia-Pascual, S. Simal, and C. Rosello. 2003. Effects of heat treatment and dehydration on bioactive polysaccharide acemannan and cell wall polymers from Aloe barbadensis Miller. Carbohydrate Polymers 51(4): 397-409.

He, Q., L. Changhong, E. Kojo, and Z. Tian. 2005. Quality and safety assurance in the processing of aloe vera juice. Food Control 16(2): 95-104.

Kim, K. H., J. G. Lee, D. Gyuun, M. K. Kim, J. H. Park, Y. G. Shin, S. K. Lee, T. H. Jo, and S. T. Oh. 1998. The development of a new method to detect the adulteration of commercial aloe gel powders. Arch. Pharmacal Res. 21(5): 514-520.

Lee, K. Y., S. T. Weintraub, and B. P. Yu. 2000. Isolation and identification of phenolic antioxidant from Aloe barbadensis Miller. Free Radical Biol. and Med. 28(2): 261-265.

Leung, M. Y. K., C. Liu, L. F. Zhu, Y. Z. Hui, B. Yu, and K. P. Fung. 2004. Chemical and biological characterization of a polysaccharide biological response modifier from Aloe vera $\mathrm{L}$. var. sinensis (Haw.) Berg. Glycobiology 14(6): 501-510.
Loret, C., V. Meunier, W. J. Frith, and P. J. Fryer. 2004. Rheological characterization of the gelation behavior of maltodextrin aqueous solutions. Carbohydrate Polymers 57(2): 153-163.

Madan, J., A. K. Sharma, and R. Singh. 2009. Fast dissolving tablets of aloe vera gel. Trop. J. Pharm. Res. 8(1): 63-70.

Miranda, M., H. Maureira, K. Rodriguez, and A. Vega-Galvez. 2009. Influence of temperature on the drying kinetics, physicochemical properties, and antioxidant capacity of Aloe vera (Aloe barbadensis Miller) gel. J. Food Eng. 91(2): 297-304.

Nindo, C. I., and J. Tang. 2007. Refractance Window dehydration technology: A novel contact drying method. Drying Tech. 25(1): 37-48.

Nindo, C. I., T. Sun, S. W. Wang, J. Tang, and J. R. Powers, 2003. Evaluation of drying technologies for retention of physical quality and antioxidants in asparagus (Asparagus officinalis L.). J. Food Sci. and Tech. (LWT) 36(5): 507-516.

Qiu, Z., K. Jones, M. Wylie, Q. Jia, and S. S. Orndorff. 2000. Modified Aloe barbadensis polysaccharide with immunoregulatory activity. Planta Medica 66(2): 152-156.

Ramachandra, C. T., and P. S. Rao. 2008. Processing of aloe vera leaf gel: A review. American J. Agric. Biol. Sci. 3(2): 502-510.

Ramachandra, C. T., and P. S. Rao. 2009. Equilibrium sorption isotherms of aloe vera gel powder. Trans. ASABE 52(3): 901-906.

Simal, S., A. Femenia, P. Llull, and C. Rosello. 2000. Dehydration of aloe vera: Simulation of drying curves and evaluation of functional properties. J. Food Eng. 43(2): 109-114.

Tewa-Tagne, P., S. Briancon, and H. Fessi. 2007. Preparation of redispersible dry nanocapsules by means of spray-drying: Development and characterization. European J. Pharm. Sci. 30(2): 124-135.

Turner, C. E., D. A. Williamson, P. A. Stroud, and D. J. Tally. 2004. Evaluation and comparison of commercially available Aloe vera L. products using size exclusion chromatography with refractive index and multi-angle laser light scattering detection. Intl. Immunopharmacol. 4(14): 1727-1737.

Vinson, J. A., H. Al Kharrat, and L. Andreoli. 2005. Effect of Aloe vera preparations on the human bioavailability of vitamins $\mathrm{C}$ and E. Phytomed. 12(10): 760-765.

Waller, T. A., R. P. Pelley, and F. M. Strickland. 2004. Industrial processing and quality control of Aloe barbadensis (aloe vera) gel. In Aloes: The Genus Aloe, 139-205. T. Reynolds, ed. Boca Raton, Fla.: CRC Press.

Yaron, A., E. Cohen, and S. M. Arad. 1992. Stabilization of aloe vera gel by interaction with sulfated polysaccharides from red microalgae and with xanthan gum. J. Agric. Food Chem. 40(8): 1316-1320. 